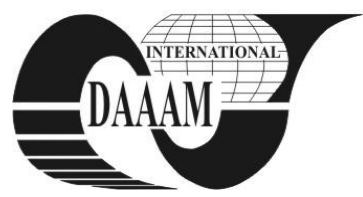

\title{
ENSURING MEASUREMENT UNITY IN THE FIELD OF DIMENSIONAL NANOMETROLOGY
}

\author{
BARSIC, G[orana]; SIMUNOVIC, V[edran] \& KATIC, M[arko]
}

\begin{abstract}
The major problem related to ensuring measurement unity in the field of dimensional nanometrology can be addressed to lack of norms that defines characteristics of measurement standards for that field of metrology.

In Laboratory for precise measurements of length (LFSB) significant efforts have been made in order to investigate metrological characteristics of standards in the field of microand nanometrology. In this paper we present results of intensive work and research carried out in LFSB in order to develop standard in the field of dimensional nanometrology that will significantly contribute to the insurance of measurement unity in that field of metrology.
\end{abstract}

Key words: nanometrology, standardization, measurement unity

\section{INTRODUCTION}

In the last two decades there has been a strong development of measurement equipment in the area of surface metrology, particularly the development of scanning microscopes.

Manufacturers of measuring equipment supplies, along with the instrument, standards that are designed specifically for that measuring device in order to verify the accuracy and to make calibration of that instrument. In addition, in the market there are several manufacturers of standards in the field of dimensional nanometrology. In general, those standards are intended for individual groups of measuring instruments, such as interferometric microscopes, stylus instruments, scanning electron microscopes or scanning probe microscopes. In the field of micrometrology requirements for the reference standards are defined by the standard [1]. The above mentioned standard set the foundation of standardization in the field of micrometrology, while the assured traceability's are accompanied by the adopted levels of measurement uncertainties. However, in the area of nanometrology further intensive work and research is necessary in order to introduce standardization, and respectively ensure traceability and measurement unity at the global level.

\section{CALIBRATION STANDARDS IN THE FIELD OF MICRO- AND NANOMETROLOGY}

As previously discussed, in area of nanometrology special problem represent the lack of standardization for calibration standards. In order to list and to make certain systematization of standards used today in the field of micro- and nanometrology a huge effort is required. The biggest step in that direction was made by the Physikalisch-Technische Bundesanstalt (PTB). In their tabulated synopsys [2] currently available artifacts which may be used as standards and which are suitable for the calibration of stylus or optical instruments and SPM's are listed.

Following the overview of standards from [2] a few facts needs to be pointed out. The first is certainly the choice of materials used for the structure of standards. In $75 \%$ cases it is a silicon or silicon dioxide.
There is also the common use of coatings, with no material that can be underlined with respect to its frequency. Materials used as a choice for coating of $\mathrm{Si}$ and $\mathrm{SiO}_{2}$ structures are $\mathrm{Cr}$, $\mathrm{Ni}, \mathrm{Si}_{3} \mathrm{~N}_{4}, \mathrm{Pt}, \mathrm{Ir}, \mathrm{W}$ or $\mathrm{Au}$.

As for measuring structures they are truly diverse and we can found them in the form of steps, grooves, honeycomb, lattice structure, models of chess boards or CD replicas, etc. Also reported measuring ranges vary considerably from standard to standard in vertical, as well as in lateral directions.

The common characteristic to listed standards is the small dimensions of the standards themselves. In the case of rectangular form, lengths of the sides do not usually exceed 10 mm.

But the main rule from the standards overview is that they are intended only for one type of measuring instruments that are designed for and as such cannot be measurable on other types of measuring instruments. So there are standards that are intended solely for scanning probe microscopes and, because of their miniaturization, they cannot be used on stylus instruments. Furthermore, there are standards with measurement area suitable for contact measurements, but do not meet the requirements for optical measurements or tunneling current measurements.

\section{DEVELOPMENT OF NEW LFSB NANO- ROUGHNESS REFERENCE STANDARD}

New LFSB nano-roughness calibration standards have two measurement areas to ensure the ability to measure the groove depths as well as 2D and 3D roughness parameters in the field below $50 \mathrm{~nm}$. One surface is a sequence of rectangular $\mathrm{SiO}_{2}$ grooves, while the second measurement area consists of three wide rectangular $\mathrm{SiO}_{2}$ grooves. Grooves with different lateral sizes are chosen so that the calibration standard could be measured by different types of instruments.

The size of the probe dimensions were considered in the design of measurement areas. Both measuring surfaces will have the same nominal value of the groove depth, thus ensuring link between them. This characteristic, as far as authors know, makes them unique.

The impact of the measured calibration standard in the uncertainty budget calculation is one with the most influence. For this reason, reduction of the measurement area was considered in order to help ensure better uniformity of standards measuring surfaces.

Since LFSB has more than 20 years of good experience with $\mathrm{Si} / \mathrm{SiO}_{2}$ as a material for standard's structures, and the fact that silicon is today the most used material for calibration standards in the field of dimensional nanometrology, new LFSB roughness standards will also be made from silicon.

Due to the transparency and electrical non-conductivity of the $\mathrm{SiO}_{2}$ layer, $\mathrm{Si} / \mathrm{SiO}_{2}$ structures must be coated with a thin metallic layer that will provide conditions for optical measurements and measurements that requires electrical conductivity of the measurement surface. 
Therefore select layer must provide following properties: excellent mechanical properties; good adhesion; maintain the geometry of the primary structure of $\mathrm{Si} / \mathrm{SiO}_{2}$ (same level of deviation from parallelism and flatness); required optical properties and electrical conductivity.

Coating with the appropriate material will assure all necessary conditions for the implementation of a range of different measuring methods on a single measurement surface. The selected coating material that has all the necessary properties is chromium.

In cooperation with company MikroMasch Trading OU and Ruđer Bošković Institute a new roughness reference standards were realized (Figure 1).

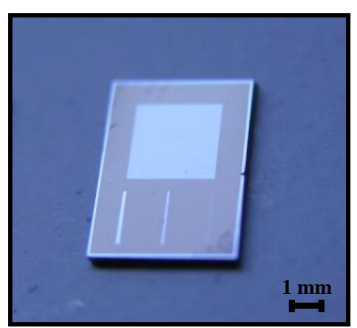

Fig. 1. New roughness reference standard

LFSB has begun with a research of standard's measuring properties. In order to explore standards an appropriate measurement were conducted. Standards were measured using the contact profilmeters, atomic force microscope, interference microscope, ellipsometer and scanning tunneling microscope (STM). Measurements preformed by use interference microscope confirmed suitability of measuring surfaces for optical measurements. The geometry of the interference fringes' indicate the uniformity of measured $\mathrm{Si} / \mathrm{SiO}_{2}$ structures (Figure 2).

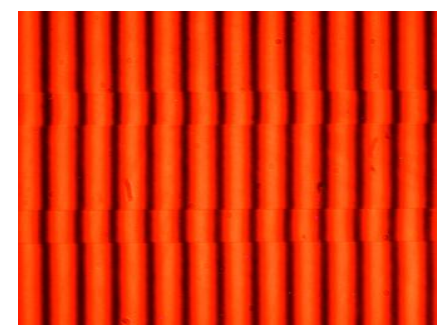

Fig. 2. Interferogram on new roughness reference standard

Measurements carried out on the profilometers confirmed the suitability of the measuring surface for the implementation of contact measurements. A measured profile (Figure 3) shows that a variation of the profile in the $\mathrm{z}$-axis does not exceed 1.5 $\mathrm{nm}$ both inside and outside of the groove.

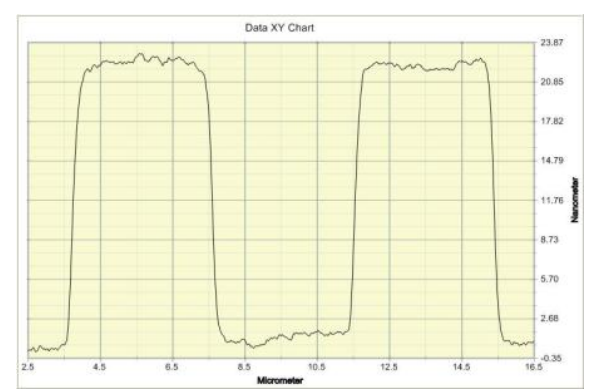

Fig. 3. Part of the profile taken with stylus profilometer

In order to investigate suitability of new roughness reference standard for measurements that requires electrical conductivity of the measurement surface, measurement were performed using scanning tunneling microscope. Figure 4 shows a segment of one groove scanned by STM on the surface with a sequence of grooves.

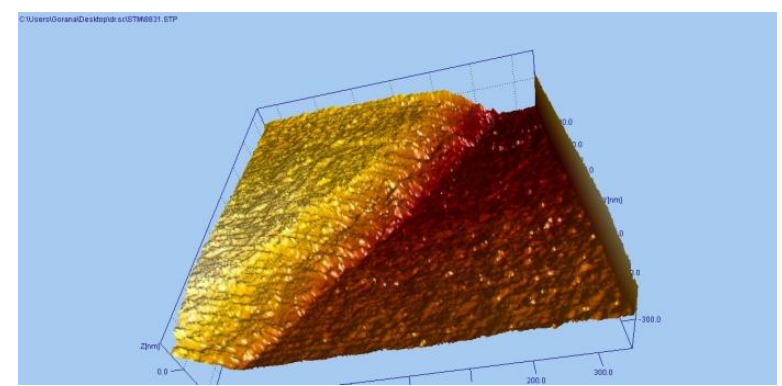

Fig. 4. A segment of one groove scanned by STM

So far conducted measurements of $2 \mathrm{D}$ roughness parameters ( $R a, R q, R m a x$ and $R z), 3 \mathrm{D}$ roughness parameters ( $S a, S q$ and $S z$ ) as well as groove depth $d$ measurements indicate the exceptional quality of standard's measuring features. LFSB will continue with the extensive research of new roughness reference standards through measurements of groove depths and $2 \mathrm{D}$ and $3 \mathrm{D}$ roughness parameters within a comparisons that will involve a large number of measuring devices i.e. measurement methods. Further research will focus on exploring measuring surface uniformity in terms of its applicability for the reproduction of $2 \mathrm{D}$ and $3 \mathrm{D}$ roughness parameters in the field below $50 \mathrm{~nm}$.

\section{CONCLUSION}

Based on the information's from the available scientific literature in the field nanometrology standards are generally intended for individual groups of measuring instruments that are designed for and as such cannot be measured on other types of measuring instruments.

The new LFSB nano-roughness reference standards have two measurement areas to ensure the ability to measure the groove depth, and 2D and 3D roughness parameters below 50 $\mathrm{nm}$. The high demands on the uniformity of measuring surfaces are assured by means of planar technology by forming grooves in silicon dioxide. In order to answer to the problem of transparency and electrical non-conductivity of the $\mathrm{SiO}_{2}$ grooves, standards were coated with a thin chromium layer.

Thus, realized measuring surface of the new roughness reference standards provide requirements for contact measurements (high hardness, good adhesion of the coating), optical measurements (non-transparency, high reflectivity) and measurements that requires electrically conductive surface. In that way realized standards are measurable on almost the entire measuring equipment in the area of nanometrology that represents a significant contribution to the development of that area.

\section{REFERENCES}

ISO 5436-1:2000 Geometrical Product Specifications (GPS) Surface texture: Profile method; Measurement standards Part 1: Material measures

Review of Standards November (2009). Available from: http://nanoscale.de/standards/techniques.htm

Leach, R. K.; Boyd R.; Burke, T.; Danzebrink, H.; Dirscherl, K.; Dziomba, T.; Mark Gee, T.; Koenders, L.; Morazzani, V.; Pidduck, A.; Roy, D.; Unger, W. \& Yacoot, A. (2010). Consultation on a European Strategy for Nanometrology

Bhushan B (Ed.), Handbook of Nano-technology $2^{\text {nd }}$ Edition (2007). Springer, ISBN 978-3-540-29855-7, New York

Koenders, L.; Dziomba, T.; Thomsen-Schmidt, P. \& Wilkening, G. (2005). Standards for the Calibration of Instruments for Dimensional Nanometrology in Nanoscale Calibration Standards and Methods, Wiley-VCH, ISBN 08194-5983-6, Weinheim 